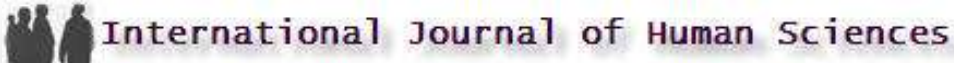

\section{Acquisition of Turkish demonstrative pronouns in children}

\author{
Meltem Muşlu ${ }^{1}$
}

\begin{abstract}
Joint focus of attention is one of the most crucial elements in effective communication. Demonstrative pronouns (DPs) have an important role in providing this joint focus of attention. Although demonstratives are a prevalent topic, not many studies are conducted to find out the developmental stages of them. Therefore, the current study attempts to find out children's comprehension of DPs in Turkish. Based on the results of the study, children's developmental stages in different age groups are provided. Turkish has a three-way distinction in its demonstrative pronoun system: $b u$ (this), $s u$ (this/that) and $o$ (that). The subjects of the study were 12 children of ages 3,4 and 5. The results of the study were intriguing and they showed that learning the demonstrative system in Turkish might follow U-shaped learning pattern. Also, the results seem to support egocentrism hypothesis that children under the age of six had difficulty in shifting the deictic center when they and the experimenter have a different perspective. The use of $s u$ at the age of 4 also showed surprising results.
\end{abstract}

Keywords: Demonstrative pronouns; Egocentrism; First language acquisition, Deixis

\section{Introduction}

To communicate effectively, participants must have a shared knowledge of what is being talked about. 'Deixis is perhaps the most useful gear in reflecting the relationship between language and context' (Zhao, 2007; 537). Deictic terms include personal pronouns; such as ' $\mathrm{I}$ ' and 'you', demonstratives; such as 'this' and 'that', and some adverbs indicating place and time; such as 'here' and 'tomorrow'. Deictic terms usually appear along with physical expressions. When talking, speakers make use of a variety of nonlinguistic cues, for instance eye-gaze and gestures. About age one and onwards, children can utilize nonlinguistic cues, which has a crucial role in children's acquisition of deictic terms (Zhao, 2007).

Deixis seems critical for our ability to learn a language, yet it is one of the most understudied core areas of pragmatics and we have no adequate cross-linguistic typology of most 
Muşlu, M. (2015). Acquisition of Turkish demonstrative pronouns in children. International Journal of Human Sciences, 12(1), 417-426. doi: $10.14687 /$ ijhs.v12i1.3104

kinds of deictic expression (Levinson, 2004). As Zhao (2007) states, previous studies related to demonstratives do not broadly focus on the developmental stages of them; therefore, the aim of this study is to find out the developmental stages of (Turkish) demonstratives in children.

\section{Properties of Demonstratives}

"Demonstratives are deictic expressions that serve specific syntactic functions" (Diessel, 1999; 2, a). They serve two related functions: They indicate the location of a referent relative to the deictic, and they serve to coordinate the interlocutors' joint attentional focus (Diessel, 2006). Demonstratives occur in four different syntactic contexts: (i) they are used as independent pronouns in argument position of verbs and adpositions, (ii) they may co -occur with a noun in a noun phrase, (iii) they may function as verb modifiers, and (iv) they may occur in copular and nonverbal clauses (Diessel, 1999, b). Demonstratives also serve specific pragmatic functions, primarily used to focus the hearer's attention on objects or location. They are characterized by specific semantic features. As Passonneau (1991) states, the referent of a demonstrative pronoun is not completely determined by the context and the semantic rules. Non-linguistic cues are required, such as a physical or vocal gesture to something in the immediate discourse circumstances. Demonstratives can refer to anything in the context that can be demonstrated.

Diessel (2006) argues that demonstratives should be kept apart from the two basic types of linguistics expressions; namely content words and grammatical markers, since they constitute a unique class of linguistic expressions serving one of the most fundamental functions in language: coordinating the interlocutors' joint focus of attention, which is one of the most basic functions of human communication.

Demonstratives are universal (Diessel, 2006). There are at least two demonstratives that are proximal and distal in all languages (Diessel, 1999a). Proximal demonstratives are used to indicate objects close to the speaker, such as 'this' in English; whereas, distal demonstratives are used to indicate objects further from the speaker, such as 'that'. Studies related to demonstratives in different languages can be found in literature. Although the studies are mostly conducted in English, some studies related to other languages, such as Japanese, Turkish, Chinese and Dutch can also be found.

Nauroka (2006) investigated the use demonstratives ko, so and $a$ in Japanese. The results of the study suggested that demonstratives can exhibit and emphasize an interactional meaning, such as the speaker's antipathy, insult, suspicion, surprise, and affection toward the referent.

Piwek, Beun, \& Cremers (2007) examined the differences between distal and proximal singular and plural demonstrative terms in Dutch. They found that important objects were pointed at 
Muşlu, M. (2015). Acquisition of Turkish demonstrative pronouns in children. International Journal of Human Sciences, 12(1), 417-426. doi: $10.14687 /$ ijhs.v12i1.3104

significantly more often than less important objects. They pointed out that the use of proximals versus distals needs explanation in terms of what speakers $d o$ when they use a proximal or a distal. In their dynamic and action-oriented approach, the difference between the two lies in what the speaker is doing.

Hasegawa (2007) looked at the demonstratives ko-so-a in soliloquil Japanese. The results showed that so- is used when the speaker does not know the referent well (only with conceptual knowledge), while $a$ - is used when s/he knows it well (with experiential knowledge). Ko- and $a$ occur in soliloquil with or without an antecedent. However, dividing their occurrences into deixis and anaphora according to the presence or absence of an antecedent is deemed arbitrary. When a certain mental imagery emerges in their consciousness, the speaker refers to it deictically with ko- or $a-$

In their study Özyürek \& Kita (2000; cited in Küntay 2007) investigated the use of demonstratives in Turkish. They suggested that Turkish presents an interesting contrast to many languages in that the demonstrative pronoun usage is sensitive not only to distance of the referent with respect to the speaker (i.e., the contrast between $b u$ and $o$ ), but also to the attentional status of the addressee with respect to the referent. That is, ş is used only when the addressee's eye gaze or attentional indicators are not yet directed towards the referent.

Ögeyik (2007) also investigated the Turkish demonstratives. She looked at how the analyses of deictic expressions in Turkish facilitate to develop textual and contextual understanding and to determine the point of view in narrative texts. She concluded that the way we interpret the textual meaning may vary and deictic expressions are the clues for describing and interpreting texts. They also refer to linguistic elements of a discourse which expand their meaning within the discourse situation.

Küntay \& Özyürek (2006) investigated the development of linguistic forms, along with nonverbal cues, by examining how the use of demonstratives is learned in Turkish. A comparison of the demonstrative use by Turkish children ( 6 four- and 6 six-year-olds) and 6 adults during conversation was made. The results showed that adult like use of attention directing demonstrative $s u$ is not mastered even at the age of six, while the distance contrasts are learned earlier. They concluded that designing referential forms in consideration of recipient's attentional status during conversation is a pragmatic feat which takes more than six years to develop.

Zhao (2007) looked at the developmental stages of Chinese demonstratives zhege (this) and nage (that). Two children from different age groups; three, four, five and six, participated in the study. The results of the study suggested that acquisition of demonstratives is a gradual process and some 
Muşlu, M. (2015). Acquisition of Turkish demonstrative pronouns in children. International Journal of Human Sciences, 12(1), 417-426. doi: $10.14687 /$ ijhs.v12i1.3104

children as young as six already know how to adapt to the speaker's point of view to comprehend the Chinese demonstratives.

As seen in literature, different studies focused on the use and developmental stages of demonstratives in different languages. Turkish is one of the languages that the use of demonstratives studied in moderation. Although some studies have been conducted to find out the developmental stages of demonstratives, they did not focus on the ages between 3 and 5. Küntay and Özyürek (2006) looked at the developmental stages of DPs in children at the age of 4 and 6, and concluded that DPs are not fully learned until the age of 6 . However, none of the studies in my knowledge looked at the developmental stages of DPs between the ages 3 and 5. Therefore, the purpose of the current study is to find out the developmental stages of demonstrative pronouns in Turkish between the ages of 3 and 5 .

\section{Research Questions}

1) What are the developmental stages of Turkish demonstratives at the ages of 3,4 , and 5 ?

2) Is there any age effect in children's comprehension of Turkish demonstratives?

\section{The demonstrative pronoun system in Turkish}

As stated previously, Turkish has a three-way distinction in its DP system: $b u$, ș and $o$. Kornfilt (1997) describes the demonstrative pronoun system in Turkish as $b u$ is used for objects that are proximal to the speaker, s $\boldsymbol{U}$ is used for objects at mid-distance or close to the addressee, and $o$ is used for objects at a far distance from the speaker. Özyürek and Kita (2000) broadened this description by investigating videotaped data. They concluded that presence or absence of joint attention is a significant factor in determining which DP to use. $S u$ is used where there is no previous joint attention between the interlocutors regardless of the distance of the object. $B u$ and $o$ are used when there is joint attention: $b u$ is used for proximal objects, whereas $o$ is used for distal objects with respect to the speaker.

\section{Method}

\section{Subjects}

The subjects of the study were 12 nursery school children. It is stated that children cannot demonstrate adult-like competence in their use of demonstratives until the age of six or seven (Clark and Şengül 1978; cited in Küntay 2002; Küntay 2006). Therefore, to examine children's developmental stages and age differences in their use of demonstratives, children aging between three and five were chosen. They were divided into three age groups, each of which consists of four 
Muşlu, M. (2015). Acquisition of Turkish demonstrative pronouns in children. International Journal of Human Sciences, 12(1), 417-426. doi: $10.14687 /$ ijhs.v12i1.3104

children. All the participants were monolingual Turkish speakers and all were individually tested in their classroom at their school. Table 1 below shows the subjects of the study.

Table 1: Subjects of the study

\begin{tabular}{l|c|c|c}
\hline Groups & Age of children & Mean age & Number of children \\
\hline Group 1 & 3 & $3 ; 5$ & 4 \\
Group 2 & 4 & $4 ; 2$ & 4 \\
Group 3 & 5 & 5 & 4 \\
\hline
\end{tabular}

\section{Materials}

Three toys with similar size and colors were chosen not to distract the students' attention. The toys were unisex to appeal the girls and boys; such as fish, a snowman and a small ball.

\section{Procedure}

The task was composed of two trials. In the first one, the experimenter sat beside the child in front of a desk (the same perspective trial), and in the second one, the experimenter sat at the opposite side of the desk (the different perspective trial).

The toys were put on the desk; the fish was placed nearer the experimenter's side of the desk, the snowman experimenter furthest from the experimenter and the ball in the middle of the snowman and the fish. Each trial required children to make a choice among the tree toys. The child first received eighteen testing sentences (randomized order) in the same perspective trial, six of bu (with and without a non-linguistic cue), six of $s u$ (with and without a nonlinguistic cue) and six of $o$ (with and without a nonlinguistic cue), and then the child received the same sentences in the different perspective trial. Each sentence was said three times to make sure that the children did not respond (in) correct by chance. In the analysis, if the child responded two sentences (out of three) correctly, it counted as correct; conversely, if they responded two sentences (out of three) incorrect, it counted as incorrect. Sentences are said randomly without starting with a cue in order not to direct the children from the first sentence. To start the experiment, the experimenter told the child that they were going to play a role-play game. She said that they would go to a toyshop to buy some toys and the child should pick up the toy the experimenter wanted to help her since she was carrying heavy bags. The testing sentences were Bana bunu verir misin? (Can you give me this?) Bana onu verir misin? (Can you give me that? or Bana şunu verir misin? (Can you give me this/that?). If the testing sentence was the one with a non-linguistic cue, the experimenter gave a clear eye gaze at the correct object; if it was the one without a nonlinguistic cue, the experimenter looked directly at the child, avoiding any gestural cues or eye-gazing. As shown in Figure 1, to start 
the task, the experimenter first sat at position 1 (the same perspective trial) and then after the same perspective trial, the experimenter moved to position 2 to begin the different perspective trial. The toys were placed about an arm's reach of the children and the responses of the children were recorded for the analysis.

Position 2

\begin{tabular}{|c|} 
snowman \\
ball \\
fish \\
\hline
\end{tabular}

Position 1 Child

Figure 1: Situation Used in the Comprehension Task

\section{Results and Discussion}

The results of the study can be seen in Tablo 2 and Table 3. Table 2 shows the children's responses with a clear cue and Table 3 shows the children's responses without a cue. Wrong responses are shown with an '-' and correct responses are shown with an ' + '. For each demonstrative, there are four signs (' - or ' ' + ') in each group representing the use of demonstratives by the children in different age groups.

\section{Table 2. Children's Responses With Cue}

\begin{tabular}{|l|c|c|c|c|c|c|}
\hline \multirow{2}{*}{$\begin{array}{l}\text { Age group } \\
(\mathrm{N}=4)\end{array}$} & \multicolumn{3}{|c|}{ Same Perspective } & \multicolumn{3}{c|}{ Different Perspective } \\
\cline { 2 - 7 } & $\mathrm{Bu}$ & Şu & $\mathrm{O}$ & $\mathrm{Bu}$ & Şu & $\mathrm{O}$ \\
\hline 3 years old & ++++ & ++-+ & ++++ & +++- & ++-+ & ++++ \\
\hline 4 years old & ++++ & ++++ & ++++ & ++++ & ++++ & ++++ \\
\hline 5 years old & ++++ & ++++ & ++++ & ++++ & ++++ & ++++ \\
\hline
\end{tabular}

As seen in Table 2, with a clear cue, except two children aged 3 in the same and different perspective trail, all the children gave correct responses. One child in the same and different perspective trails gave incorrect responses to $s u$. Besides these, all the children responded the questions correctly. As stated previously, children do not learn DP system fully not until the age of 6 , the reason of them responding correct is obviously the clear cue- eye-gaze, provided by the experimenter. Physical expressions, such as eye-gaze or pointing, may play a central role in assisting children to work out meanings of words (Zhao, 2007). Also, as Küntay and Özyürek (2006) point out, children have sensitivity to eye-gaze status with age and the use of $s u$ is learned beyond the age of 6. In order to have a better picture on the developmental stages of DPs in children, the children 
Muşlu, M. (2015). Acquisition of Turkish demonstrative pronouns in children. International Journal of Human Sciences, 12(1), 417-426. doi: $10.14687 /$ ijhs.v12i1.3104

are also asked to choose the correct toys without a clear cue-eye-gaze. The results of children's responses without a clear cue are presented in Table 3 below.

Table 3. Children's Responses Without Cue

\begin{tabular}{|l|l|l|l|l|l|l|}
\hline \multirow{2}{*}{$\begin{array}{l}\text { Age group } \\
(\mathrm{N}=4)\end{array}$} & \multicolumn{3}{|c|}{ Same Perspective } & \multicolumn{3}{c|}{ Different Perspective } \\
\cline { 2 - 7 } & $\mathrm{Bu}$ & $\mathrm{Su}$ & $\mathrm{O}$ & $\mathrm{Bu}$ & Şu & $\mathrm{O}$ \\
\hline 3 years old & +--- & ---- & ---- & ---- & ---- & +--- \\
\hline 4 years old & ++++ & +-++ & +-++ & +--- & --++ & --+- \\
\hline 5 years old & --++ & --+- & +-++ & -+-- & -+-- & -+-- \\
\hline
\end{tabular}

As seen in the table above, none of the children at the age of 3 answered the questions correctly for $s u$ and $o$ in the same perspective trail and $b u$ and $s u$ in the different perspective trail. Only one child answered the questions for $b u$ in the same perspective trail and $o$ in the different perspective. The children at the age of 4 had full control over the production of DPs in the same perspective. All the four-year-old children gave correct answers for $b u$, and most of them gave correct answers for $s u$ and $o$. However, in the different perspective trail, most of them could not give correct answers for $b u$ and $o$ and half of them gave correct answers for $s u$. When the 3 and 4year-old children's responses were compared, it was seen that four-year-olds performed better than the three-year-olds. It is not surprising that they performed better than the younger ones since as Zhao (2007) states; the control over DPs improves steadily with age. However, when the five-yearold children's answers for the questions are looked at, surprising results were found. As seen in the results, five-year-old children performed worse than the four-year-olds both in the same and different perspective trails. It was expected that five-year-old children's performance would be the best among the three groups since the control over DPs increase with age. The reason for the fiveyear-olds' doing worse than four-year-olds could be the U-shaped pattern of development. In Ushaped learning, the learner first learns a given target behavior, then unlearns it and finally relearns it. As Küntay and Özyürek (2006) found, pre-school children (at the age of 4 and 6) demonstrate adult like competence in their production of $b u$ and $o$ in terms of marking distance contrasts. In their study, they did not look at the performance of children at the age of five. Therefore, it is possible that children start learning to use DPs correctly at the age of four, then they use it incorrectly at the age of 5 and finally use them correctly again at the age of six; showing U-shaped pattern of development.

When the same and different perspective trails are compared, it is seen that children in all age groups performed worse in the different perspective trail. This result is not surprising and it is consistent with literature. As Zhao (2007) concludes in his study, children think in an egocentric way. Children in his study also responded correctly to this in the same perspective trail; whereas they 
Muşlu, M. (2015). Acquisition of Turkish demonstrative pronouns in children. International Journal of Human Sciences, 12(1), 417-426. doi: $10.14687 /$ ijhs.v12i1.3104

responded it wrong in the different perspective trail. Between the ages of 2 and 7 , children think in an egocentric way; they think they are the center of the world and they fail to acknowledge any perspectives other than their own. Therefore, it is not surprising that they were not speakercentered but child-centered in the different perspective trail.

The use of $s u$ in the recent study is intriguing. Mothers use şu less frequently when they talk to their children; leaving them with inadequate opportunities to figure out the usage of $s u$ (Küntay and Özyürek, 2006). Therefore it is not surprising that the children age of 3 and 5 performed better in the use $b u$ and $o$ besides the five-year-olds in the different perspective trail. However, the use of $s u$ at the age of 4 is surprising. Küntay and Özyürek (2006) stated that şu is learned beyond the age of 6. Yet, in the current study, the four-year-old children performed better than the five-year-old children. The reason for this, as stated previously, might be U-shaped learning development.

\section{Conclusion}

The aim of this study was to find out the developmental stages of Turkish demonstratives. In order to reach that aim, 12 children from different age groups (3,4 and 5) were chosen and an experiment was conducted with them.

The results of the study showed that physical cues have a crucial role in figuring out the meaning of demonstrative pronouns. The children in all age groups performed better when physical cue was provided. Their performance varied when physical cue was not provided.

Although the results of the current study cannot be generalized, it was found that four-yearold children performed better than the three-year-olds. This is not surprising since as Zhao (2007) states; the control over DPs improves steadily with age. However, when the five-year-old children's answers for the questions are looked at, surprising results were found: five-year-old children performed worse than the four-year-olds both in the same and different perspective trails. The reason for the five-year-olds' doing worse than four-year-olds could be the U-shaped pattern of development. As Küntay and Özyürek (2006) found, pre-school children (at the age of 4 and 6) demonstrate adult like competence in their production of $b u$ and $o$ in terms of marking distance contrasts. In their study, they did not look at the performance of children at the age of five; therefore, it is possible that children start learning to use DPs correctly at the age of four, then they use it incorrectly at the age of 5 and finally use them correctly again at the age of six; showing Ushaped pattern of development. However, in order to come to a correct conclusion, a similar should also be conducted with six-year-olds.

When the same and different perspective trails are compared, it is seen that children in all age groups performed worse in the different perspective trail. This is consistent with literature and 
Muşlu, M. (2015). Acquisition of Turkish demonstrative pronouns in children. International Journal of Human Sciences, 12(1), 417-426. doi: $10.14687 /$ ijhs.v12i1.3104

it is not surprising since as Zhao (2007) states, children think in an egocentric way. Therefore; they were not speaker-centered but child-centered in the different perspective trail.

The results for the use of $s \xi$ in the recent study are intriguing. It is not surprising that the children age of 3 and 5 performed better in the use $b u$ and $o$, besides the five-year-olds in the different perspective trail. The reason could be the input children receive. As Küntay and Özyürek (2006) states, mothers use şu less frequently when they talk to their children; leaving them with inadequate opportunities to figure out the usage of $s u$. However, the use of $s \xi$ at the age of 4 is surprising. Küntay and Özyürek (2006) stated that su is learned beyond the age of 6. Yet, in the current study, the four-year-old children performed better than the five-year-old children. The reason for this, as stated previously, might be U-shaped learning pattern.

The current study provides insights into the learning process of demonstrative pronouns in children of ages 3,4 and 5. Since the results cannot be generalized, further studies should be conducted with more children and different age groups should also be included.

\section{References}

Clark, E., \& Şengül (1978). Cited in: Küntay, A., \& Özyürek, A. (2002). Joint Attention and the development use of the use demonstrative pronouns in Turkish. BUCLD 26 Proceedings. ed. Barbora Skarebela et. Al. 336-347. Somerville, MA: Cascadilla Press.

Diessel, H. (1999, a). Demonstratives: Form, Function and Grammaticalization. John Benjamin Publishing: Amsterdam, Netherlands.

Diessel, H. (1999, b). The Morphosyntax of Demonstratives in Synchrony and Diachrony. Linguistic Typology 3, 1-49. Doi: 1430-0532/99/003-00

Diessel, H. (2006). Demonstratives, Joint Attention, and the Emergence of Grammar. Cognitive Linguistics, 17 (4): 463-489. Doi: 10.1515/COG.2006.015

Hasegawa, Y (2007). Demonstratives in Soliloquial Japanese. Proceedings of the 43rd Annual Meeting of the Chicago Linguistic Society, Chicago, USA.

Levinson, S. C. (2004). Deixis. Handbook of Pragmatics. Oxford: Blackwell Publishing.

Küntay, A., \& Özyürek, A. (2006). Learning to Use Demonstratives in Conversation: What Do Language Specific Strategies in Turkish Reveal? Journal of Child Language, 33, 303-320. doi:10.1017/S0305000906007380

Kornfilt, J. (1997). Turkish. London: Routledge.

Nauroka, K. (2006). The interactional functions of the Japanese demonstratives in conversation. Pragmatics, 16,4.475-512.

http://elanguage.net/journals/pragmatics/article/view/523/443

Ögeyik, M. C. (2007) Deictic Expressions and the Types of Deixis in Turkish Narratives. The International Journal of Language Society and Culture, 22, 8-19.

URL: www.educ.utas.edu.au/users/tle/JOURNAL/ 

12(1), 417-426. doi: $10.14687 /$ ijhs.v12i1.3104

Özyürek, A., \& Kita, S. (2000). Attention Manipulation in the Situational Use of Turkish and Japanese Demonstratives. Paper presented at the Linguistic Society of America Conference, Chicago, In: Kuntay, A (2007) Disassembling the Puzzle Using the Crosslinguistic Methodology: Koç Üniversitesi Dergisi (2).

Passonneau, P. J. (1991). Some Facts about Centers, Indexicals, and Demonstratives. In Proceedings of the $29^{\text {th }}$ Annual meeting of the ACL: 633-70. Berkeley.

Piwek, P., Beun, R., \& Cremers, A. (2007). 'Proximal' and 'distal' in Language and Cognition: Evidence from Deictic Demonstratives in Dutch. Journal of Pragmatics, Electronically published. Doi: 10.1016/j.pragma.2007.05.001

Zhao, Y. (2007). Children's Acquisition of Demonstrative Pronouns in Mandarin Chinese. http://dspace.wul.waseda.ac.jp/dspace/bitstream/2065/29095/1/PACLIC 2100056 Z hao.pdf 